\title{
Rapid estimation of cryptic adult abundance and breeding dynamics in a critically endangered elasmobranch from close-kin mark recapture
}

Patterson TA (1), Hillary R (1), Feutry P (1), Gunasakera R (1), Marthick J (2), Pillans RD (3)

1. CSIRO Oceans and Atmosphere, Castray Esplanade Battery Point, TAS 7004, Australia

2. Menzies Institute for Medical Research, University of Tasmania, Hobart, TAS, 7000, Australia.

3. CSIRO Oceans and Atmosphere, St Lucia, Queensland, Australia

\begin{abstract}
Elasmobranchs are one of the most highly-threatened vertebrate taxa. Estimating abundance of spawning adults is often extremely challenging, yet crucial for prioritization of conservation measures. Emblematic of these challenges, the speartooth shark (Glyphis glyphis, Müller and Henle, 1839) was initially known only from rare specimens collected in a few tropical regions river systems of Australia and Papua New Guinea. Listed as critically endangered in Australia (where only six adults have ever been recorded) and endangered by the IUCN, such scarcity and limited distribution prevent direct assessments of abundance or reproductive biology. We used close-kin mark-recapture to estimate the abundance of mature G. glyphis in a genetically isolated population in the Wenlock River, Queensland, Australia. From 224 juvenile/sub-adults and 2 adult samples taken over three years (2013-2016), 46 half-sibling and 33 full-sibling pairs were found. The adult population was estimated at 897 (80\% Credible interval $531-1684)$ with a sex ratio (based on mitochondrial DNA) highly skewed to males (females -0.09 : males -0.91 ). Based on juveniles sampled in different years that shared a mother, $71 \%$ of females were estimated to skip-spawn. In an average year we estimate 44 breeding females occupy the system. Importantly, these methods constitute a viable and relatively rapid approach to obtain robust estimates of absolute abundance and other key population parameters for similar rare species.
\end{abstract}




\section{Introduction}

2 A fundamental quantity to monitor in conservation settings is the abundance of breeding adults.

3 Yet, in some species, breeding aged individuals can be cryptic, even if juveniles may be

4 encountered. This study considers a member of the genus Glyphis, the river sharks, which are

5 found the western Indo-Pacific (Li et al. 2015), Papua New Guniea (White et al. 2015) and

6 Northern Australia (Thorburn and Morgan 2004; Compagno, White, and Last 2008; Stevens,

$7 \quad$ Pillans, and Salini 2005; Pillans et al. 2009). For over a century the three species in this genus

8 were known only from type specimens collected in the 19th century and were generally

9 considered extinct (Li et al. 2015). Following discovery of Australian species, G. glyphis and G.

10 garriki in the late 20th century, the species were conservation listed under IUCN listing and in

11 Australia under the Environmental Protection of Biodiversity and Convseration (EPBC) act of

12 1999, due to their apparently limited range and rarity. In Australia and Papua New Guinea only 6

13 adult G. glyphis individuals have ever been recorded (Pillans, unpublished data; White et al.

14 2015).

15 If species as secretive and poorly understood as river sharks are subject to anthropogenic

16 influence, their populations may be put at risk before their status is even established (Haque and

17 Das 2019). When data collection rates are very slow, conventional survey methods such as visual

18 surveys, mark-release-recapture are often infeasible or simply too slow to establish baseline

19 abundance. In marine systems, non-target species are often monitored only via trends in bycatch

20 data from commercial fisheries(e.g. Jordaan, Santos, and Groeneveld 2018). The problems of

21 characterising non-target populations from fisheries data are well documented. These difficulties

22 are further exacerbated in the case of rare, long-lived and low productivity species both through 
23 difficulties in collecting observations but also since specimens are rarely collected, basic

24 biological parameters- age/growth and maturity are generally unable to be established. In such

25 situations, conservation listing advice must resort to use of data collected haphazard data

26 collection or expert opinion (Friedman et al. 2018; Friedman et al. 2019). The limitations of this

27 are clear and yet obviously remain difficult to overcome and hence typically remain in place as

28 the best available basis for precautionary management. Indeed, elasmobranchs, rare or otherwise,

29 exemplify this problem: Dulvy et al (2014) found that of 1041 species considered only 389 were

30 not at risk of extinction. Crucially however, the study also noted that nearly half of all species

31 were considered data deficient, clearly indicating a need for methods that can address severe

32 uncertainty for a group which are broadly at risk due to their widely noted life history

33 characteristics (Reynolds et al. 2005).

34 Close-kin mark-recapture (CKMR) (Bravington et al. 2016) is a technique that addresses many

35 of these issues. It seeks to find closely-related kin-pairs in a sample of individuals from a given

36 population. The number of close-relatives parent-offspring pairs or half siblings, is directly

37 related to abundance of breeding-aged individuals in the population. CKMR has been applied to

38 assess population abundance in a highly migratory marine teleost, Thunnus maccoyii

39 (Bravington, Grewe, and Davies 2016) and for Australasian white shark, Carcharodon

40 carcharias (Hillary et al. 2018; Bruce et al. 2018). A recent study (Ruzzante et al., 2019) has

41 verified the approach against standard mark-recapture approaches. These studies have

42 demonstrated the utility of CKMR in very different settings; a highly abundant, highly migratory

43 teleost targeted by a multinational fishery; and a relatively scarce elasmobranch and a freshwater

44 teleost. Kinship information has also been used to establish generational connectivity (Palsbøll,

45 Zachariah Peery, and Berube 2010; Feutry et al. 2017) 
46 In this study we examine an isolated population of elasmobranch, the speartooth shark (Glyphis

47 glyphis) known to occur in only a few river systems throughout Northern Australia and Papua

48 New Guinea (Pillans et al. 2009). Glyphis glyphis was described from a single specimen without

49 locality and was subsequently found to be synonymous with the Bizant River shark (Glyphis sp.

50 A). In Australia, the species was first recorded from the Bizant River in Queensland where it has

51 not been detected since and is thought to be extinct. Glyphis glyphis is typical of many sharks

52 and rays which use tropical estuaries and rivers for parts of their life cycle (Lyon et al. 2017).

53 The population of G. glyphis examined here occupies the Wenlock River system which lies on

54 the western side of Cape York, Queensland and is subject to a highly seasonal flow regime

55 (Leigh and Sheldon 2008). The system comprises the Wenlock and Ducie rivers and empties into

56 the Gulf of Carpentaria (Figure 1). The genetic isolation of the local G glyphis populations was

57 established by Feutry et al (2017) who used kinship data gathered from mitogenomes and

58 genome-wide SNP data from the same samples considered in this study as well as samples from

59 several rivers in the Northern Territory, far to the west of the Wenlock. Feutry et al., found

60 strong support for river fidelity in juveniles in females. In these Northern territory rivers, males

61 were found to father offspring in several rivers indicating a degree of movement. However, there

62 were no kin-pair linkages from the NT populations and the Wenlock.

63 Like many euryhaline species that utilize estuaries and rivers as nursery areas, juvenile

64 speartooth shark are confined to these habitats for several years before presumably moving into a

65 marine environment. The six Australian and Papua New Guinea adults have only been recorded

66 in marine environments (Pillans, unpublished data; White et al 2015). Members of the Genus

67 attain large size ( $>2.5 \mathrm{~m} \mathrm{TL})$ and like other carcharhinid sharks of similar size and life history, 
68 most likely have low reproductive output and late maturation. However, since only six adults

69 have ever been reported, virtually nothing is known about litter size and reproductive periodicity.

70 As we shall demonstrate in the following, CKMR based on half-sibling pairs detected within

71 samples of mostly non-reproductive animals, produced estimates of adult abundance, sex ratio,

72 and provide insight into reproductive periodicity and provide information on litter size from full-

73 sibling pairs.

\section{Methods}

\section{Sampling and genetics methods}

76 Capture and sampling of G. glyphis was conducted under a CSIRO animal ethics permit

77 (A11041; A2-2016; 2017-04). Juvenile G. glyphis (52-160 cm TL) were captured with rod and

78 line in the estuarine reaches of the Wenlock and Ducie River (Figure 1). Neonate sharks were

79 easily recognised by the presence of an umbilical scar and otherwise animals were assigned to an

80 estimated age-class based on length and date of capture. We used a combination of growth data

81 from neonate sharks recaptured over seven years and Given the rarity of the Data data on length

82 at age were obtained from $10 \mathrm{G}$. glyphis from the Adelaide River, NT, that were aged from

83 vertebral sections (P. Kyne, unpublished data).

84 The processing of the nuclear genetic data followed the method employed in Hillary et al (2018)

85 and Bruce et al (2018), where the quality control, kin-finding statistical methods are outlined in

86 detail. Briefly, this method compares every individual shark with all others which could feasibly

87 be a related sibling and computes a Pseudo Log-odds (PLOD) score which characterizes likely

88 kin- type as being either unrelated, full-sibling or half-siblings. Note that HSPs and grandparent- 
89 grandoffspring are genetically indistinguishable with unlinked SNP markers (Thompson 2000)

90 and so age data needs to be employed to distinguish true HSPs. Mito-Genome sequencing was

91 also examined using a PCR approach so that each HSP could be categorized as likely paternal or

92 maternal.

\section{Estimates for adult abundance}

94 The approach to estimating abundance and other population parameters proceeds by specifying

95 the population dynamics, and then using maximum likelihood, to estimate the most likely

96 abundance, survival rates etc. given the observed kin-pair data. In the following we describe the

97 population model and outline the statstical estimation approach. Full details of the estimation

98 methods are given in Appendix A.

\section{Population dynamics}

100 The abundance dynamics were assumed to follow a simple exponential growth model split by

101 sex:

$$
N_{s, t}=N_{s, 0} \exp \left(\lambda_{s} t\right)
$$

103 where $\lambda_{s}$ is the logarithmic rate-of-change, $N_{s, 0}$ the initial abundance at some given reference

104 year, and the annual adult survival probability is $\phi_{s}$. The subscripts $s$ and $t$ are sex and time,

105 respectively. Note that we did not expect to see appreciable population growth over the series of

106 cohorts captured by the data. Accordingly, and after initial model and data exploration, $\lambda$ was set

107 to 0 , therefore we estimate $N_{0}$ as a constant breeding abundance. 


\section{Accounting for non-annual female spawning}

109 It is known that many sharks skip-spawn - i.e. do not spawn annually - especially in females

110 (Domeier and Nasby-Lucas 2007; Bansemer and Bennett 2009; Pillans et al. 2021). Note that, by

111 skip spawning we do not mean a random chance that, in any given year, a female might choose

112 to reproduce (or not) depending on individual factors such as body condition. That particular

113 case does not bias the chance of finding HSPs (Bravington et al. 2016). Instead, we mean that the

114 spawning cycle is fixed at a $>1$ year frequency for at least some proportion of the female

115 population. For this systematic case, some fraction of the adult female population, $\psi$ (maximum

116 1) operates on a non-annual breeding cycle. Here we allowed for a two year female breeding

117 cycle. Therefore an unknown proportion of the population may spawn on even years and the

118 remainder in odd. Assuming it to be a random process as to which cycle an individual belongs to,

119 then of the total $N$ adults, if we have $\psi=1$ then only $N / 2$ are on average ever reproducing in a

120 given year. The effective adult reproducing population, $\widetilde{N}$, in a given year is a function of $\psi$.

$$
\widetilde{N}=\frac{N(2-\psi)}{2}
$$

122 For $\psi=0$ (every adult female reproduces every year), by definition $\widetilde{N}=N$.

123 The probability of being a maternal HSP now depends upon $|c 1-c 2|$, where $c_{1}$ and $c_{2}$ are the

124 cohorts in the comparison, so if $\left|c_{1}-c_{2}\right|$ is even, then following Hillary et al (2018), the

125 probability of a maternal $\operatorname{HSP}(M H S P)$ is

$$
P\left(M H S P \mid c_{1}, c_{2}\right)=\frac{\phi^{|c 1-c 2|}}{\widetilde{N}}
$$

127 When $\left|c_{1}-c_{2}\right|$ is an odd number then 


$$
P\left(\operatorname{MHSP} \mid c_{1}, c_{2}\right)=\frac{(1-\psi) \phi^{\left|c_{1}-c_{2}\right|}}{\widetilde{N}}
$$

129 For the extreme case of population-wide skip-spawning $(\psi=1)$ there is zero chance of MHSPs

130 for odd gaps between birth years and twice as much chance as finding HSPs for even numbered

131 gaps because half the population is not reproducing that year. For the $\psi=0$, then effectively $\psi$

132 dissapears from the equations. In this study we examined this skip spawning model (spawning

133 occurs every 2 years for proportion $\phi$ of females) and the non-skip model obtained by fixing

$134 \psi=0$.

\section{Abundance Log-likelihood}

136 Estimating the log-likelihood of the parameters $\lambda, \phi$ and $N_{0}$ requires comparison of each

137 individual in the data to all others to determine if they are either an Unrelated Pair (UP), Full-

138 sibling Pair (FSP) or a Half-Sibling Pair (HSP). In determining the probability of $i$ and $j$ sharing

139 at least one parent, we must account for the survival rate of the adults over the time elapsed

140 between their respective birth years. In doing this we also obtain information about the adult

141 survival rate, $\phi^{A}$. Clearly, for an FSP to be found we expect that $i$ and $j$ are memebers of the

142 same cohort, i.e. share the same birth year. Hence the key covariates for each $\{i, j\}$ juvenile

143 comparison are their respective years of birth: $\mathbf{z}=\left\{z_{i}, z_{j}\right\}$. In brief the likelihood of the

144 parameters is given by:

$$
\mathcal{L}(\boldsymbol{\theta} \mid \mathbf{Z})=\sum_{i} \sum_{j} \log \left(p_{i j}^{k i n}\right)
$$


146 where $p_{i j}^{k i n}$ is the probability that individuals $i$ and $j$ are of a given kin-type and $\boldsymbol{\theta}$ are unknown

147 parameters to be estimated, including the abundance, mortality rate and population growth rate.

148 Full details of the probabilities of kinship used in the likelihood calculations (see Appendix A).

149 In order to estimate abundance, growth or mortality in this model, various other factors of the

150 sampling process that leads to kin pairs must be accounted for. This entails the following extra

151 parameters in the model which in one sense are "nuisance" parameters, but in many respects also

152 contain interesting information regarding the reproductive processes at play. Appendix A gives

153 details of how these are factored into the likelihood calculations. Here we simply describe the

154 rationale for their inclusion.

155 - Given that the model is structured by sex, we estimate the sex ratio $\zeta$, the proportion of

156 females in the adult population.

157 - There is high potential for over-representation of within-cohort maternal kin (FSPs and

158 MHSPs) given high heterogeneity in very early-life survival. For example: some litters may

159 by chance suffer zero mortality from predators, bycatch or other factors. Another may be

160 subject to heavy mortality. We parameterise this through a term $v$ which, following Hillary

161 et al (2018), we term the "litter effect" parameter.

162 - Multiple paternities are likely given understanding of other elasmobranchs (Feldheim,

163 Gruber, and Ashley 2004; Portnoy et al. 2007). The parameter $\theta$ is the probability that a

164 mother will mate with more than one male in a given year.

165 - Similarly, $\gamma$ is a parameter which describes multiple paternity. It is an estimate of the 166 number of different females an individual father is expected to breed with in a given year. 
167 Hence, the full set of unknown parameters is $\boldsymbol{\theta}=\left\{N_{0}, \lambda, \phi^{A}, \nu, \gamma, \zeta, \psi\right\}$. Estimation of these

168 parameters was carried out using the R package 'TMB' (Kristensen et al. 2015). Posterior

169 samples on model estimates were generated using the R package 'tmbstan' (Monnahan and

170 Kristensen 2018).

171 Further, to consider the influence of sex ratio on the abundance estimates, we also employed a

172 simple estimator of abundance accounting for sex ratio (see Appendix B) and used this to

173 explore what effect misestimation of sex ratio (e.g. through uncertainty due to low mtDNA

174 diversity) might have on adult abundance.

\section{Results}

\section{Kin pair data}

177 Data from 229 animals captured between 2013-2016 was used in this study. These consisted of

178110 females and 109 males. The samples ranged between 48 and 226cm (Total length).

179 These samples generate $N_{\text {comp }}=N_{\text {samples }} *\left(N_{\text {samples }}-1\right) / 2$ comparisons between individuals

180 and in this case, $N_{\text {comp }}=5995$. From these the kin-finding methods based on the PLOD statistics

181 (fig 2), that 5916 unrelated pairwise comparisons and the presence of 33 FSP and 46 HSP in the

182 sampled individuals. Attributing age-at-length to these suggested that the earliest HSP was made

183 up of an individual from the 2007 cohort. The cohorts observed in the HSPs spanned 6 years,

184 with $76 \%$ being from cohorts within a 0-2 year interval. All full sibling pairs were from within

185 the same cohorts (Figure 3). There were 23 kin clusters in the observed data and 15 FSP-only

186 clusters. The maximum number of FSP's from the same year was 5 individuals which were all 
187 litter mates. Given the probability of sampling all juveniles from a litter is low when only 30

188 samples taken in a year, it is possible that this provides an estimate of the lower bound on litter

189 size for this species. The mtDNA data reflected very low haplotype diversity with only 2

190 haplotypes detected. These occurred in roughly equal proportions in all samples (type $1=51.7 \%$ :

191 type2 $=48.3 \%$ ). Within FSP these were equally split again, but in HSP there was a

192 preponderance of type 2 (type $1=37 \%$ : type $2=63 \%$ ).

\section{Abundance estimates model estimates}

194 The median-posterior estimate of adult abundance was 897 breeding individuals for the system

195 with wide credible intervals (Table 1). The maximum a posteriori estimate at just over 500

196 (Figure 5a). We would therefore conclude the breeding population in the Wenlock river consists

197 of 500-1000 individuals. However, the sex ratio parameter (Table 1) was highly skewed toward

198 males with an estimated sex ratio of $92 \%$ male: $8 \%$ Female. Therefore the male abundance

199 median estimate is 825.65 (95\% CI: 358.67-2517.53), which imples that the number of breeding

200 females is less than 100 individuals (Median: 72, 95\% CI: 18-206 ). Again there is uncertainty

201 around these estimates, but the model predicts a highly male-skewed sex ratio.

202 To gauge the interaction between sex-ratio and abundance estimates, we also considered an

203 alternate and simple approach using a more basic estimator of population size (see appendix B).

204 This indicate similar results for estimated total adult abundance ( $\approx 850$ adult individuals).

205 Additionally we used it to determine what the likely effect of uncertainty or bias in our mtDNA

206 results (specifically, the low diversity with only 2 haplotypes at 50:50 ratio). The results show

207 that if the true sex ratio in the Wenlock is closer to 50:50, then we expect a smaller population of 
208 adults (at 50:50 sex ratio, the population would be roughly half what we estimate in the full

209 model). This has important conservation implications which are considered in the discussion.

210 The multiple paternity parameter $\theta$ was low $(0.06,95 \% \mathrm{CI}: 0.01-0.21)$. This indicates a low

211 probability that breeding females mate with multiple partners in a given year. Accordingly the

212 male-linked parameter $\gamma$, estimating the number of female partners per year for males was

213 approximately 4 (95\% CI: 1-17). The absence of cross-cohort FSPs indicates that there is

214 apparently a low likelihood of individual mothers and fathers breeding together over different

215 years. Additionally, the estimate of the skip spawning parameter strongly supported a large

216 portion of the females obligately skip spawning. The skip spawning parameter was estimated at

$217 \psi=0.7(95 \% \mathrm{CI}: 0.41-0.85)$. Note that cross cohort HSP at a 1 year gap were most common

218 (1-2 year gaps accounted for $52 \%$ of the observed HSPs).

\section{Model fit diagnostics}

220 Two diagnostics were used to assess model fit. The first used the HSPs and haplotype data to

221 consider the predicted and observed numbers of HSP within and across cohorts that had the same

222 or differing haplotypes. There was very good agreement between the model predictions and the

223 observed numbers (table 2). The second diagnostic looked that the expected number of HSPs that

224 would be expected for a given cohort gap (Figure 4) which again showed close agreement

225 between the model predictions and the observed numbers of HSPs at a given number of gap

226 years between cohorts. From these results we consider that the model fits the data well giving

227 confidence in its predictions. 


\section{Discussion}

229 Elasmobranchs are ackowledged to be a taxa at high risk of population decline through

230 harvesting and habitat loss (Dulvy et al. 2014). This situation is exacerbated by uncertainty with

231 more than half the species assessed classified as data deficient (Collen et al. 2016). Reliable

232 calculation of either relative or absolute abundance is problematic for a great many species.

233 River sharks, prior to this study could be considered to be an extreme exemplar of these

234 difficulties. However, we showed through this study that CKMR is able to produce a robust

235 estimate of abundance of breeding individuals and other parameters of interest over the course of

236 a 4 year sampling program.

237 Maintaining a viable breeding population is obviously a crucial conservation target, yet it is not

238 an uncommon situation in elasmobranchs and other species, that assessing the number of

239 breeding adults via direct marking or survey methods is impossible. Our result also demonstrates

240 that it is possible to rigorously assess endangered and elasmobranchs where the adults are

241 effectively cryptic, so long as juvenile samples are available. That field programs were able to

242 successfully capture these individuals and thereby estimate the number of breeding individuals

243 means that these techniques could be applied to other threatened species.

244 Threats to G glyphis neonates in the Wenlock include natural local predators, such as the

245 saltwater crocodile (Crocodylus porosus) and bull sharks (Carcharinus leucas) and fishing

246 pressure from gill netting and crab trap-fishing (Pillans et al. 2009; Lyon et al. 2017). It is known

247 that $G$ glyphis are captured in these gear types (Pillans et al., in press) and typically tend to be

248 mistaken for small C leucas. Given the low breeding female abundance from the present study,

249 there is strong potential for juvenile take to have adverse effects on the population in coming 
250 years. This is clearly an aspect of the management of the population which requires further

251 research and monitoring. We recommend studies that investigate juvenile mortality, juvenile

252 abundance and the risk posed by bycatch in commercial gill nets and commercial and

253 recreational crab fisheries that operate in the system.

254 A key result from our study that is the highly male-biased sex ratio we estimated based on the

255 mitochondrial haplotypes in FSP and HSP. There is considerable uncertainty around this result,

256 and further data is required to refine our estimate of sex ratio and the prevalance of skip

257 spawning. Preliminary work where we set the skip-spawning parameter $\psi=0$, indicated that the

258 overall adult abundance estimates remained largely unchanged, whether skip spawning was

259 included or not. The effect of including skip spawning was to increase the degree of male bias in

260 the sex ratio as skip spawning by females would reduce the average number of females breeding

261 in any given year.

262 Given these results, and the potential for the estimation process to trade-off increased precision

263 on one parameter at the expense of another, we critically examined the skewed sex ratio result by

264 considering some simple facts from our data. Taking the across-cohort case only, the two key

265 data were as follows: (1) Two haplotypes with exact 50/50 frequency in the population (which,

266 while unusual, makes the mathematics simple), and (2) 33 of the cross-cohort HSPs the same

267 haplotype while 2 did not. Consider a simple case with a stable total adult population $N_{A}$ and

268 proportion of females $\zeta$. Mortality can be ignored if we assume it is equal for each sex. Then in

269 this simple case, the probability of being a maternal HSP is then $\mathbb{P}(M H S P)=1 /(\zeta N)$ and

270 paternal $\mathbb{P}(P H S P)=1 /((1-\zeta) N)$. Now consider how we might relate this to mtDNA data.

271 When comparing two HSPs with haplotypes $h_{1}$ and $h_{2}$ (in our case, the only ones) then the

272 probability that they do have the same haplotype is: 


$$
\mathbb{P}\left(h_{2}=h_{1} \mid H S P\right)=\mathbb{P}(M H S P)+\mathbb{P}(P H S P) \times \mathbb{P}\left(h_{2}=h_{1}\right)
$$

274 The probability they have different haplotypes is:

$$
\mathbb{P}\left(h_{2} \neq h_{1} \mid H S P\right)=\mathbb{P}(P H S P) \times \mathbb{P}\left(h_{2} \neq h 1\right)
$$

276 From this one can examine what would constitute a 50/50 sex ratio in the adults by setting

$277 \mathbb{P}(M H S P)=\mathbb{P}(P H S P)=\mathbb{P}(H S P)$. Knowing that $\mathbb{P}\left(h_{2}=h_{1}\right)=\mathbb{P}\left(h_{2} \neq h_{1}\right)=0.5$ from the

$27850: 50$ haplotype frequency in the population, then the probability (assuming 50/50 sex ratio) of

279 getting a HSP that either (a) has a common haplotype is

$$
\mathbb{P}\left(h_{2}=h_{1} \mid H S P\right)=\mathbb{P}(H S P)+1 / 2 \times \mathbb{P}(H S P)=3 / 2 \times \mathbb{P}(H S P)
$$

or, (b) has different haplotype is

$$
\mathbb{P}(h 2 \neq h 1 \mid H S P)=1 / 2 \times \mathbb{P}(H S P)
$$

283 The cases (a) and (b) imply that even with a 50/50 sex ratio, the expected ratio of cases that

284 do/do not have the same haplotype is already 3:1. If there are effectively an infinite number of 285 haplotypes in the population, then a 50/50 sex ratio will converge to a 1:1 ratio in numbers of 286 HSPs that do or do not have the same haplotype. But when the haplotypes become rarer, this 287 ratio immediately starts to rise from 1:1 to much higher values. With only 2 haplotypes each 288 having $50 \%$ frequency in the population, we see $\mathrm{a} \approx 16: 1$ ratio in the number that do/do not have

289 the same haplotype, indicating far fewer females than males. Which is as we see in our model 290 estimates.

291 In fact, we can produce a simple estimate of sex ratio, purely from the observed mtDNA data 292 (i.e. with 2 haplotypes at 50\% frequency). The ratio of HSPs that have the same haplotype to 293 those that do not is $(2-\zeta) / \zeta$ so $\zeta=0.5$ gives a ratio of 3 . If we let $\chi$ be our observed HSP 
294 ratio, then our guess at the sex ratio is $\zeta=2 /(1+\chi)$ so substituting in $\chi=16$ we obtain $\zeta=$

2950.11 which was our model estimates if we set the skip-spawning proption to zero. This

296 alternative argument supports the finding that the sex ratio of G. glyphis in the Wenlock is highly

297 skewed, given the data on proportion of the HSP which had common haplotypes and the fact that

298 only 2 mtDNA haplotypes were observed.

299 In our results there were two key findings regarding breeding biology:

300 First, we estimated a distinctly male bias via the sex ratio parameter $\zeta$. But $\theta$, the female

301 probability of multiple male partners is estimated to be very low $\theta=0.06$ (95\% CI: $0.01-0.21$ ),

302 while $\gamma$, the number of female partners per male is $\sim 4$ (95\% CI: $1-17)$. The skip spawning

303 proportion $\psi \approx 0.7$ and therefore, on average, the model predicts that there are $\sim 45$ breeding

304 females in the system for a given year.

305 Second, if mating was totally random then in the absence of any other information besides a sex

306 ratio and abundance, we would expect that females might mate with multiple males ( the

307 estimates at face value suggest there are $\approx 11.5$ males per female in the population). However,

308 the extra information from the kin pairs and mtDNA in the model implies that this was not the

309 case. In fact these data suggest that female promiscuity is rare whereas males mate with multiple

310 females. But also given magnitude of $\gamma$ and the estimates population size, the model indicates

311 that not all breeding males sire offspring in a given year.

312 A situation where females mate with few partners and then do not mate again within that season

313 would be consistent with these findings. Note that the litter effect parameter is not overly large $(v$

$314=0.8-0.9)$, therefore indicating that there is not an overwhelming effect of "lucky litters." Given

315 that, we can use the estimated sex ratio and number of female breeding partners per year $(\gamma)$ to 
316 calculate the effective/expected number of breeding males as $\bar{N}_{m}=\gamma \times \zeta \times N_{0} \approx 150$. This

317 would equate to a "within year" sex ratio of 22\% F: $78 \%$ M. Clearly this is still skewed toward

318 males, but not to the extent that simplistic interpretation of the parameter estimates would

319 indicate.

320 Male-biased sex ratios do occur in vertebrate populations and examples exist in birds, mammals

321 and reptiles (Clutton-Brock 1986; Cockburn et al. 2002), although in most populations, the

322 Fisherian ratio is expected (Hamilton 1967; Charnov 1982). Occurrences of sex ratio bias have

323 been implicated in increasing risk to endangered populations (Heinsohn et al. 2019). In certain

324 reptiles, male aggression during courtship has been noted to have the effect of reducing female

325 survival rates (Le Galliard et al. 2005). In turn, the evolutionary response by breeding females

326 was to produce more male offspring as they would be expected to have higher fitness. This could

327 be an explanation for our results, given that sexual conflict has been observed in elasmobranchs

328 (Portnoy et al. 2007). However, since adults are virtually never seen, the potential to observe or

329 test such a mechanism is almost impossible in this case.

330 The estimates obtained here are consistent with a roving population of males and philopatric

331 females. Female philopatry has been observed in other Australian G. glyphis populations (Feutry

332 et al 2017) and more widely in elasmobranchs (Hueter et al. 2005; Portnoy et al. 2015; Feldheim

333 et al. 2014; Feldheim, Gruber, and Ashley 2004; Nosal et al. 2021). Thus female philopatry

334 would be expected in the Wenlock. However, a wide ranging adult male population would be

335 expected to breed in other river systems which would be expected to show up as between-river

336 kin pairs. Feutry et al (2017) found no kin-pairs were between the Wenlock and other known

337 Australian populations. The data from Feutry et al (2017) did not include samples from Papua

338 New Guinea and it is possible other rivers around the Gulf of Carpentaria which may hold $G$. 
339 glyphis and that the Wenlock population is actually reproductively connected to other locations.

340 Hence, these results indicate a need for further sampling in other systems. In the Northern

341 territory G. glyphis populations, males sire offspring between rivers but females were philopatric

342 to the same river each year (Feutry et al., 2017). Such a system might explain the male-skewed

343 sex ratios in this study, but again there are no suitable rivers north of the Wenlock apart from

344 those in Papua New Guinea. We consider this unlikely given the previous results from the

345 Northern Territory where populations $150 \mathrm{~km}$ shared a parent - but not in the same year. South

346 of the Wenlock the nearest large river is over $160 \mathrm{~km}$ away with no records of juveniles observed

347 in this system. Additionally, if unknown populations of G. glyphis were connected to the

348 Wenlock population, it would most likely be via males with females being philopatric, as per the

349 results of Feutry et al (2017). Therefore female recruits would only originate in the Wenlock

350 itself.

351 These aspects mean at most, there could be some unknown connectivity of the Wenlock

352 population by males only. Therefore reduction of numbers of females in the system would not be

353 offset by immigration. This suggests that the area is critical habitat which needs careful

354 management and monitoring on an ongoing basis, in common with many elasmobranch nursery

355 areas (Heupel et al. 2019). Previous studies have considered detailed spatial management

356 schemes for this population (Dwyer et al. 2019). However, these schemes require detailed

357 fisheries effort data and associated bycatch rates. Bycaught $G$. glpyhis are likely to be largely the

358 same juveniles and sub-adult age classes sampled here. Therefore, further investigation of

359 juvenile population abundance and mortality will be needed in order to predict long term impacts

360 on the breeding stock and the sustainability of the population. 


\section{Conclusions}

362 This study has provided a robust estimate of the breeding population of an extremely poorly

363 understood and rare elasmobranch. Our model provided insights into the breeding dynamics of

364 the population and produced some surprising results regarding the sex ratio in this population.

365 Clearly, these will require further investigation which may revise the current estimates

366 (Cockburn et al. 2002). Nonetheless, our abundance estimates were robust to these aspects and

367 point to the need to obtain information on sources of juvenile mortality in the system as well as

368 the potential for linkages to other populations. At the moment, any such conclusions regarding

369 another additional Queensland population would be premature and the proper precautionary

370 approach would be to continue to consider the Wenlock as an isolated population with as few as

371100 adult females. This and the potential for significant mortality on juveniles from fisheries

372 recently found in Pillans et al (in press) indicate a need for ongoing protection and monitoring.

\section{Acknowledgements}

374 This work was funded by the Ord River Offset project and the CSIRO.

\section{Author contributions}

376 RP conceived the study, collected field samples and conducted tagging work; PF, RG, JM

377 performed laboratory genetics work; TAP, RH conducted analysis and statistical modelling and

378 wrote the manuscript. All authors reviewed the manuscript prior to submission. 


\section{Bibliography}

Bansemer, CS, and MB Bennett. 2009. "Reproductive Periodicity, Localised Movements and Behavioural Segregation of Pregnant Carcharias Taurus at Wolf Rock, Southeast Queensland, Australia." Marine Ecology Progress Series 374: 215-27.

Bravington, MV, Grewe PM, and Davies CR. 2016. "Absolute Abundance of Southern Bluefin Tuna Estimated by Close-Kin Mark-Recapture.” Nature Communications 7: 13162.

Bravington, MV, Skaug, HJ, Anderson, EC. 2016. “Close-Kin Mark-Recapture.” Statistical Science 31 (2): 259-74.

Bruce, B, Bradford, RW, Bravington, MV, Feutry P, Grewe PM, Gunasekera R, Harasti D, Hillary RD and Patterson TA. 2018. "A National Assessment of the Status of White Sharks." CSIRO. February.

Charnov, EL. 1982. The Theory of Sex Allocation.(MPB-18), Volume 18. Princeton University Press.

Clutton-Brock, TH. 1986. “Sex Ratio Variation in Birds.” Ibis 128 (3): 317-29.

Cockburn, A., Legge S., Double MC, and others. 2002. "Sex Ratios in Birds and Mammals: Can the Hypotheses Be Disentangled." Sex Ratios: Concepts and Research Methods, 266-86.

Collen B, Dulvy NK, Gaston KJ, Gärdenfors U, Keith DA, Punt AE, Regan HM, et al. 2016. "Clarifying Misconceptions of Extinction Risk Assessment with the IUCN Red List." Biology Letters 12 (4): 20150843.

Compagno, LJV, White WT, Last PR. 2008. “Glyphis Garricki Sp. Nov., A New Species of River Shark (Carcharhiniformes: Carcharhinidae) from Northern Australia and Papua New Guinea, with a Redescription of Glyphis glyphis (Müller \& Henle, 1839)." Descriptions of New Australian Chondrichthyans, 203-25.

Domeier, ML, and Nasby-Lucas, N. 2007. “Annual Re-Sightings of Photographically Identified White Sharks (Carcharodon Carcharias) at an Eastern Pacific Aggregation Site (Guadalupe Island, Mexico)." Marine Biology 150 (5): 977-84.

Dulvy, NK, Fowler SL, Musick JA, Cavanagh RD, Kyne PM, Harrison LR, Carlson JK, et al. 2014. "Extinction Risk and Conservation of the World's Sharks and Rays." Elife 3: e00590.

Dwyer, RG, Campbell HA, Pillans RD, Watts ME, Lyon BJ, Guru SM, Dinh MN, Possingham, HP and Franklin, CE. 2019. "Using Individual-Based Movement Information to Identify Spatial Conservation Priorities for Mobile Species." Conservation Biology.

Feldheim, KA, Gruber SH, and Ashley MC\V. 2004. "Reconstruction of Parental Microsatellite Genotypes Reveals Female Polyandry and Philopatry in the Lemon Shark, Negaprion Brevirostris." Evolution 58 (10): 2332-42.

Feldheim, KA, Gruber SH, Dibattista JD, Babcock EA, Kessel ST, Hendry AP, Pikitch EK, Ashley MV, and Chapman DD. 2014. "Two Decades of Genetic Profiling Yields First Evidence 
of Natal Philopatry and Long-Term Fidelity to Parturition Sites in Sharks.” Molecular Ecology 23 (1): 110-17.

Feutry P, Berry O, Kyne PM, Pillans RD, Hillary RM, Grewe PM, Marthick JR, et al. 2017. "Inferring Contemporary and Historical Genetic Connectivity from Juveniles." Molecular Ecology 26 (2): 444-56.

Friedman, K, Gabriel S, Abe O, Nuruddin OA, Ali A, Hassan BR, Cadrin SX, et al. 2018. "Examining the Impact of CITES Listing of Sharks and Rays in Southeast Asian Fisheries." Fish and Fisheries 19 (4): 662-76.

Friedman, K, Braccini M, Bjerregaard-Walsh M, Bonfil R, Bradshaw CJA, Brouwer S, Campbell I, et al. 2019. "Informing CITES Parties: Strengthening Science-Based DecisionMaking When Listing Marine Species." Fish and Fisheries.

Hamilton, WD 1967. "Extraordinary Sex Ratios.” Science 156 (3774): 477-88.

Haque, AB, and Arka Das S. 2019. "New Records of the Critically Endangered Ganges Shark Glyphis gangeticus in Bangladeshi Waters: Urgent Monitoring Needed." Endangered Species Research 40: 65-73.

Heinsohn, R, Olah G, Webb M, Peakall R, and Stojanovic, D. 2019. "Sex Ratio Bias and Shared Paternity Reduce Individual Fitness and Population Viability in a Critically Endangered Parrot." Journal of Animal Ecology 88 (4): 502-10.

Heupel, MR, Kanno S, Martins AP, and Simpfendorfer, CA. 2019. "Advances in Understanding the Roles and Benefits of Nursery Areas for Elasmobranch Populations." Marine and Freshwater Research 70 (7): 897-907.

Hillary, RM, MV Bravington, TA Patterson, P Grewe, R Bradford, P Feutry, R Gunasekera, et al. 2018. "Genetic Relatedness Reveals Total Population Size of White Sharks in Eastern Australia and New Zealand.” Scientific Reports 8 (1): 2661.

Hueter, RE, MR Heupel, EJ Heist, and DB Keeney. 2005. "Evidence of Philopatry in Sharks and Implications for the Management of Shark Fisheries." Journal of Northwest Atlantic Fishery Science 35: 239-47.

Jordaan, GL, Santos J, and Groeneveld JC. 2018. "Effects of Inconsistent Reporting, Regulation Changes and Market Demand on Abundance Indices of Sharks Caught by Pelagic Longliners Off Southern Africa." PeerJ 6: e5726.

Kristensen, K, Nielsen A, Berg CW, Skaug H, and Bell B. 2015. "Template Model Builder TMB.” J. Stat. Softw 70: 1-21.

Le Galliard, J-F, Fitze PS, Ferrière R, and Clobert J. 2005. "Sex Ratio Bias, Male Aggression, and Population Collapse in Lizards." Proceedings of the National Academy of Sciences 102 (50): 18231-36. 
Leigh, C and Sheldon F. 2008. "Hydrological Changes and Ecological Impacts Associated with Water Resource Development in Large Floodplain Rivers in the Australian Tropics." River Research and Applications 24 (9): 1251-70.

Li, C, Corrigan S, Yang L, Straube N, Harris M, Hofreiter M, White WT, and Naylor GJP. 2015. "DNA Capture Reveals Transoceanic Gene Flow in Endangered River Sharks." Proceedings of the National Academy of Sciences 112 (43): 13302-7.

Lyon, BJ, Dwyer RG, Pillans RD, Campbell HA, and Franklin CE. 2017. "Distribution, Seasonal Movements and Habitat Utilisation of an Endangered Shark, Glyphis glyphis, from Northern Australia." Marine Ecology Progress Series 573: 203-13.

Monnahan, CC, and Kristensen K. 2018. "No-u-Turn Sampling for Fast Bayesian Inference in ADMB and TMB: Introducing the Adnuts and TMBstan R Packages." PloS One 13 (5): e0197954.

Nosal, AP, Cartamil DP, Ammann AJ, Bellquist LF, Ben-Aderet NJ, Blincow KM, Burns ES, et al. 2021. "Triennial Migration and Philopatry in the Critically Endangered Soupfin Shark Galeorhinus galeus." Journal of Applied Ecology.

Palsbøll, PJ, Peery MZ, and Berube M. 2010. "Detecting Populations in the 'Ambiguous' Zone: Kinship-Based Estimation of Population Structure at Low Genetic Divergence.” Molecular Ecology Resources 10 (5): 797-805.

Pillans, RD, Stevens JD, Kyne PM, and Salini J. 2009. "Observations on the Distribution, Biology, Short-Term Movements and Habitat Requirements of River Sharks Glyphis Spp. In Northern Australia.” Endangered Species Research 10: 321-32.

Pillans, R, Rochester WA, Babcock RC, Thomson DP, Haywood MDE, and Vanderklift M. 2021. 'Long-Term Acoustic Monitoring Reveals Site Fidelity, Reproductive Migrations and Sex Specific Differences in Habitat Use and Migratory Timing in a Large Coastal Shark (Negaprion acutidens)." Frontiers in Marine Science 8: 33.

Portnoy, DS, Piercy AN, Musick JA, Burgess GH, and Graves JE. 2007. "Genetic Polyandry and Sexual Conflict in the Sandbar Shark, Carcharhinus plumbeus, in the Western North Atlantic and Gulf of Mexico." Molecular Ecology 16 (1): 187-97.

Portnoy, DS, Puritz JB, Hollenbeck CM, Gelsleichter J, Chapman D, and Gold JR. 2015. "Selection and Sex-Biased Dispersal in a Coastal Shark: The Influence of Philopatry on Adaptive Variation." Molecular Ecology 24 (23): 5877-85.

Reynolds, JD, Dulvy NK, Goodwin NB, and Hutchings JA. 2005. "Biology of Extinction Risk in Marine Fishes.” Proceedings of the Royal Society B: Biological Sciences 272 (1579): 2337-44.

Ruzzante, DE, McCracken GR, Førland B, MacMillan J, Notte D, Buhariwalla C, Flemming JM, and Skaug H. 2019. "Validation of Close-Kin Mark-Recapture (CKMR) Methods for Estimating Population Abundance." Methods in Ecology and Evolution. 
Stevens, JD, Pillans RD, and Salini J. 2005. "Conservation Assessment of Glyphis Sp. A (Speartooth Shark), Glyphis Sp. C (Northern River Shark), Pristis microdon (Freshwater Sawfish) and Pristis zijsron (Green Sawfish)." CSIRO Marine Research, Hobart.

Thompson, EA. 2000. "Statistical Inference from Genetic Data on Pedigrees." NSF-CBMS Regional Conference Series in Probability and Statistics, International Mathematical Statistics, Beachwood Ohio.

Thorburn DC, and Morgan DL. 2004. "The Northern River Shark Glyphis Sp. C (Carcharhinidae) Discovered in Western Australia.” Zootaxa 685 (1): 1-8.

White WT, Appleyard SA, Sabub B, Kyne PM, Harris M, Lis R, Baje L, et al. 2015.

"Rediscovery of the Threatened River Sharks, Glyphis garricki and G. glyphis, in Papua New Guinea." PloS One 10 (10): e0140075. 


\section{Tables}

Table 1. Summary of model parameter estimates from posterior distributions. Values are given as median and $95 \%$ credible intervals.

\begin{tabular}{lllll} 
Parameter & Description & Median & $5 \%$ & $95 \%$ \\
\hline$N_{0}$ & Abundance & 897.45 & 365.99 & 3269.52 \\
$v$ & litter effect & 0.87 & 0.53 & 1.51 \\
$\zeta$ & sex ratio & 0.08 & 0.02 & 0.23 \\
$\theta$ & multiple paternity & 0.06 & 0.01 & 0.21 \\
$\gamma$ & female breeding partners & 3.83 & 1 & 16.93 \\
$\psi$ & skip spawning proportion & 0.7 & 0.41 & 0.85 \\
\hline
\end{tabular}

Table 2. Diagnostics of expected vs observed numbers of HSPs that did or did not have a common haplotype. The model predictions agreed closely with the data.

\begin{tabular}{llllll} 
Cohort & Within & \multicolumn{3}{c}{ Across } \\
\cline { 1 - 1 } Haplotype & Same & & Different & Same & Different \\
Observed & 40 & 4 & 33 & 2 \\
Predicted & 40.001 & & 3.999 & 32.986 & 1.999
\end{tabular}


bioRxiv preprint doi: https://doi.org/10.1101/2022 02.24 .481858 : this version posted February 27, 2022. The copyright holder for this preprint (which was not certified by peer review) is the author/funder, who has granted bioRxiv a license to display the preprint in perpetuity. It is made available under aCC-BY-NC-ND 4.0 International license.

\section{Figures}
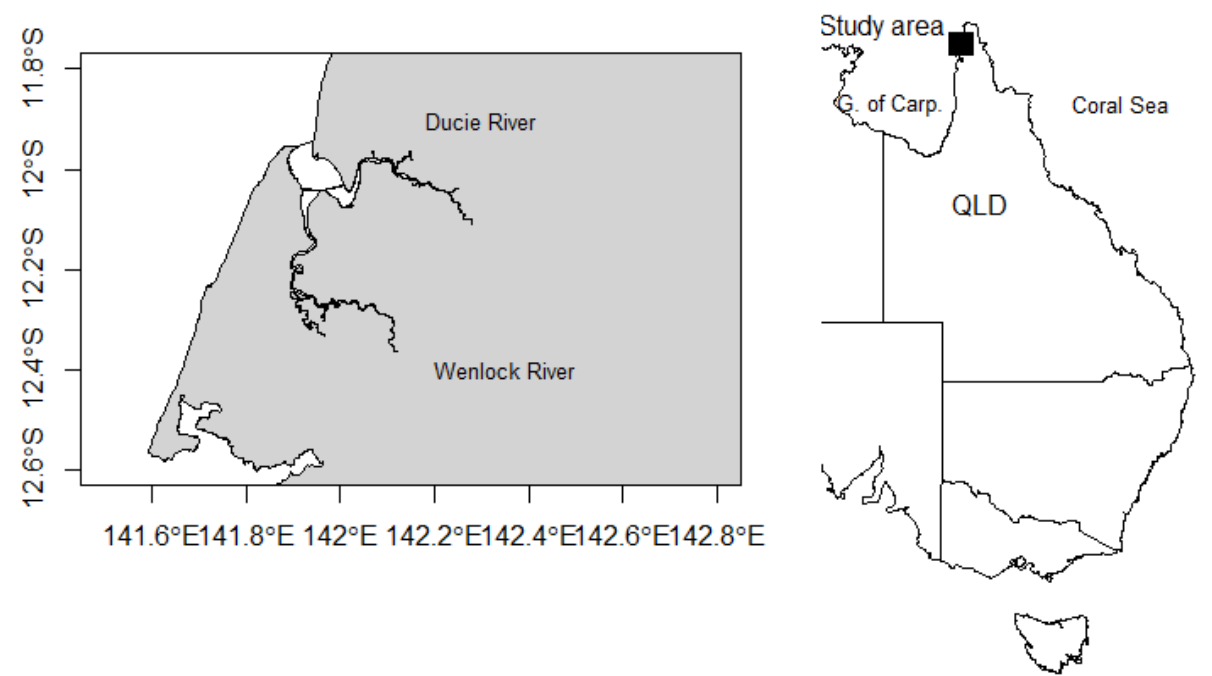

Figure 1. Map of Northern Australian region and (inset) details of the river system where samples were obtained. NT-Northern Territory and QLD - Queensland. 
bioRxiv preprint doi: https://doi.org/10.1101/2022.02.24.481858: this version posted Februarv 27. 2022. The copvriaht holder for this preprint (which was not certified by peer review) is the author/funder, who has granted bioRxiv a license to display the preprint in perpetuity. It is made available under aCC-BY-NC-ND 4.0 International license.

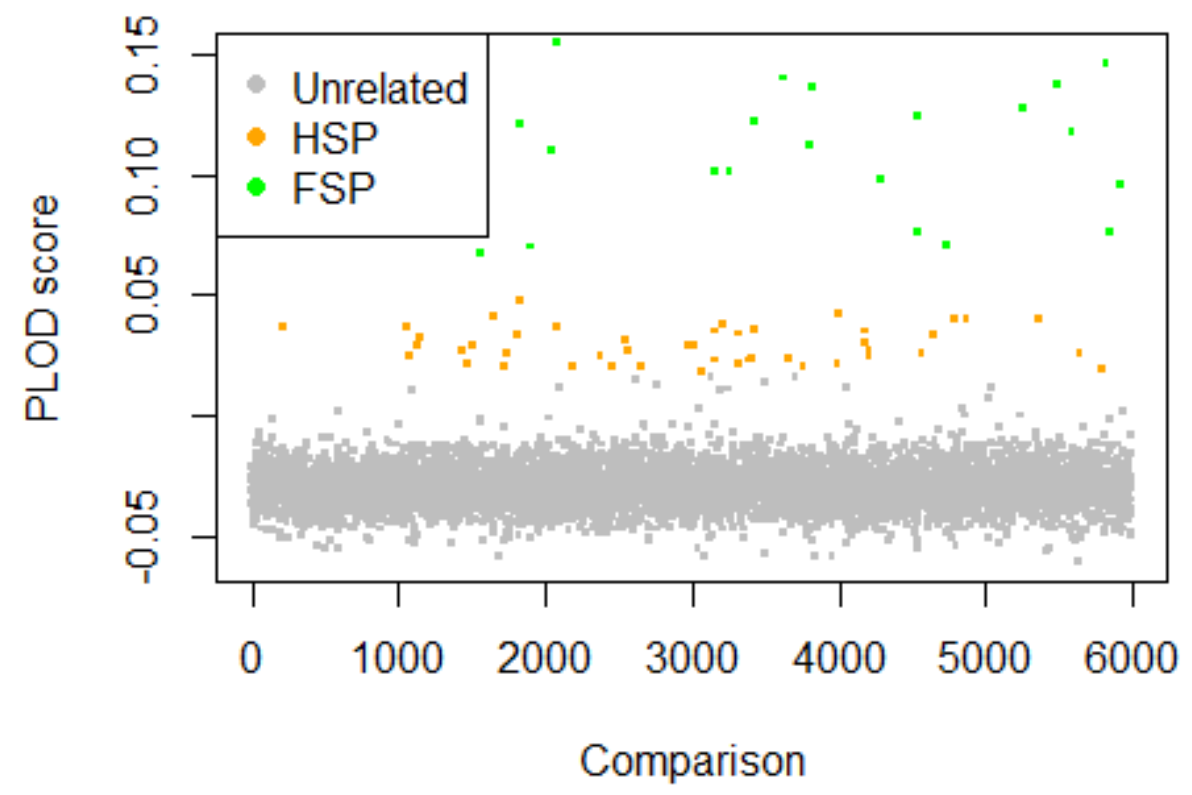

Figure 2. Psuedo-log odds (PLOD) scores for each pairwise comparison of the data. Colours denote kintypes. 


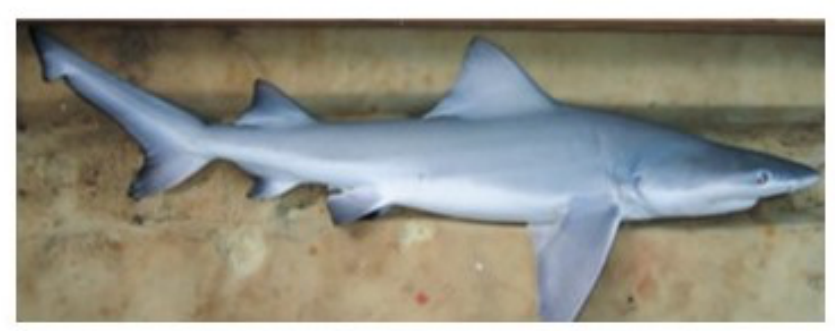

\section{Kin pairs}

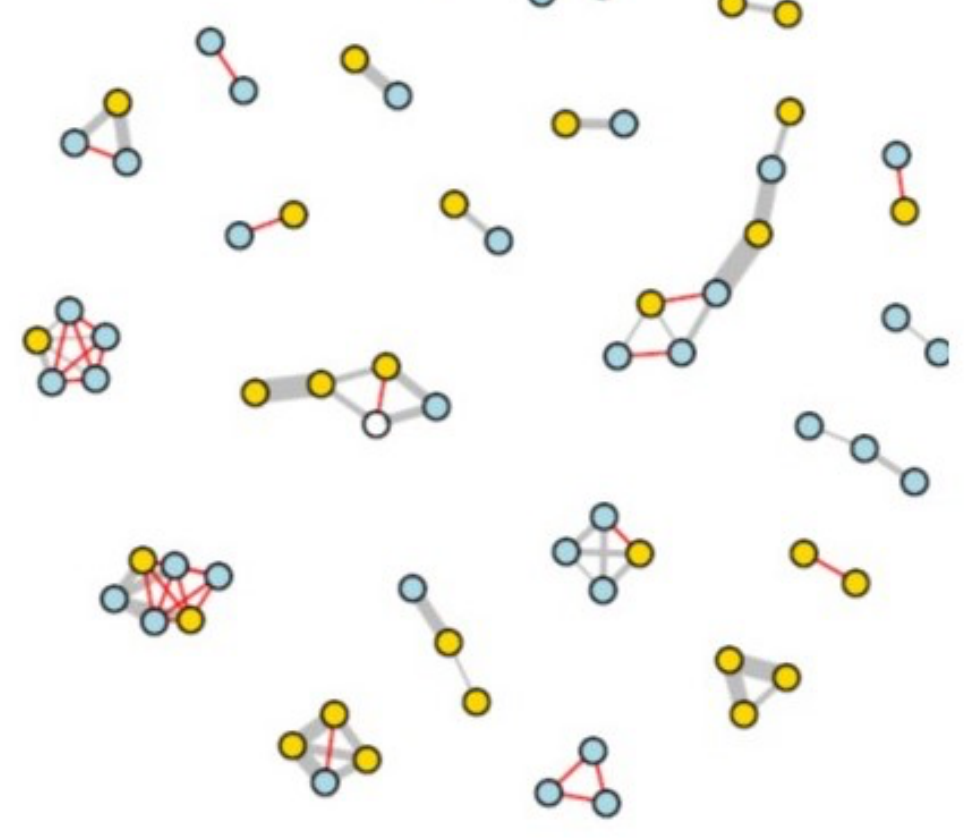

kin-type

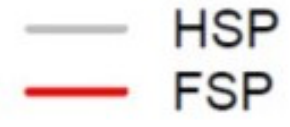

cohort gap

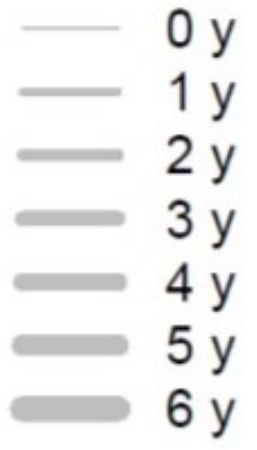

sex

\section{male female}

Figure 3. HSP and FSP Kin-relations detected from the 226 individuals. 23 clusters of related individuals were detected. Line weights denote the cohort gap in years between related individuals and the colours of edges denotes kin-type. 
bioRxiv preprint doi: https://doi.org/10.1101/2022.02.24.481858: this version posted February 27, 2022. The copyright holder for this preprint (which was not certified by peer review) is the author/funder, who has granted bioRxiv a license to display the preprint in perpetuity. It is made available under aCC-BY-NC-ND 4.0 International license.

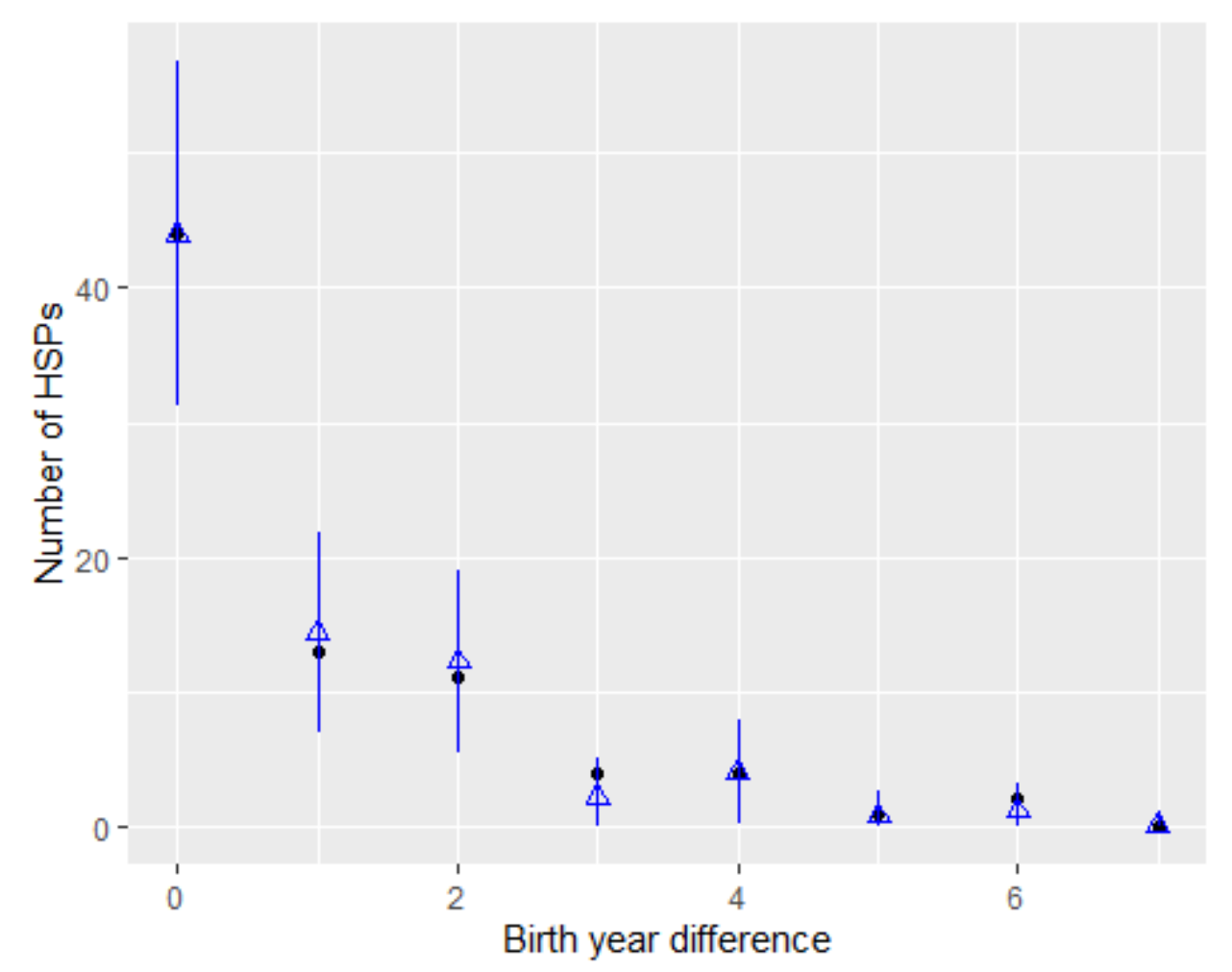

Figure 4. Diagnostics of model fit. The observed number of HSPs are given by black dots and expected numbers are given as blue triangles plus standard errors 
(a)

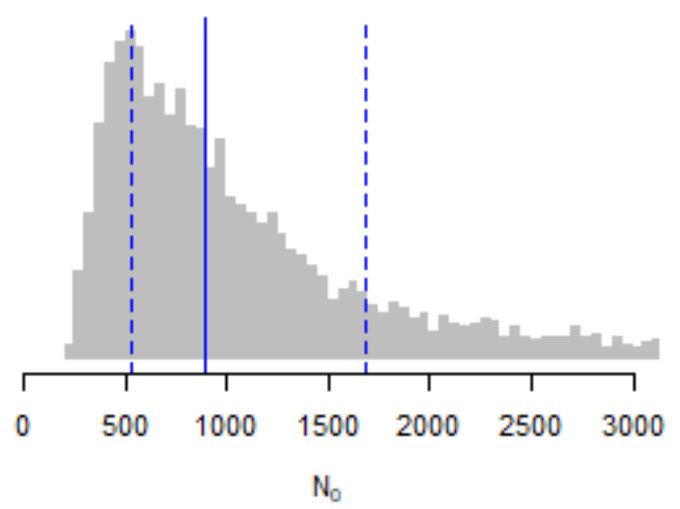

(c)

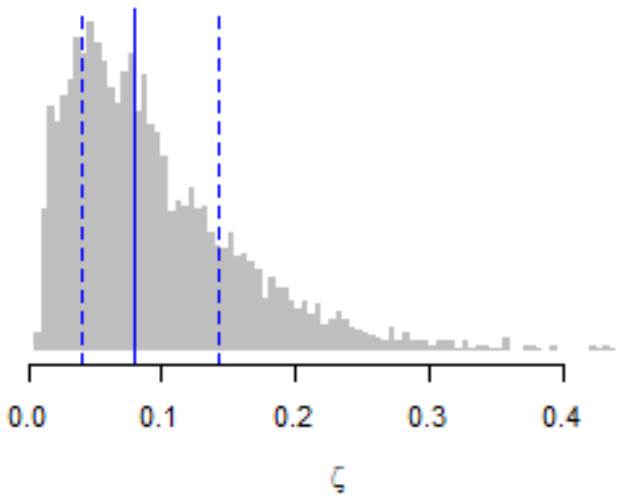

(e)

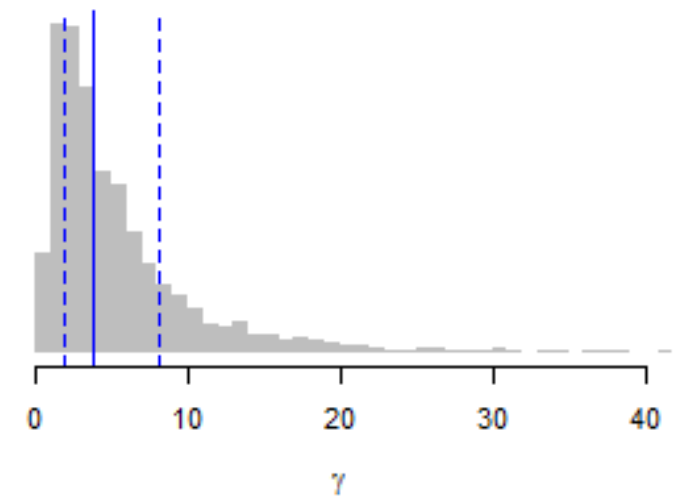

(b)

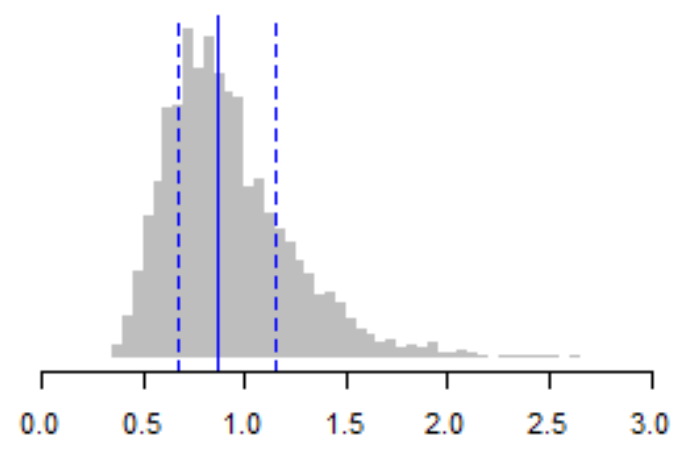

$\mathrm{v}$

(d)

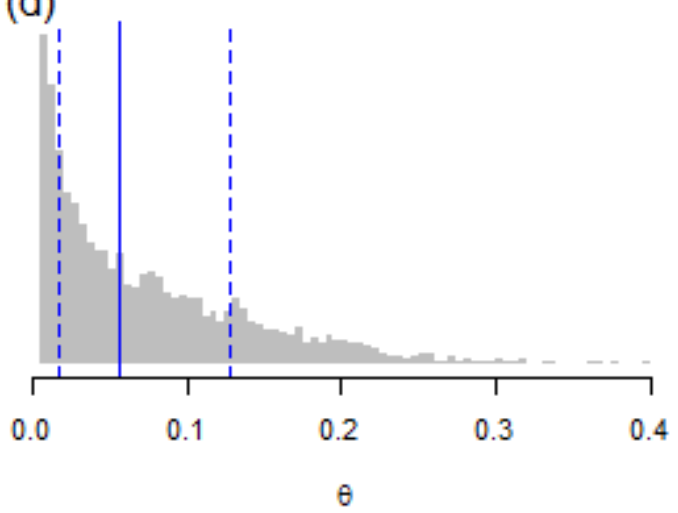

(f)

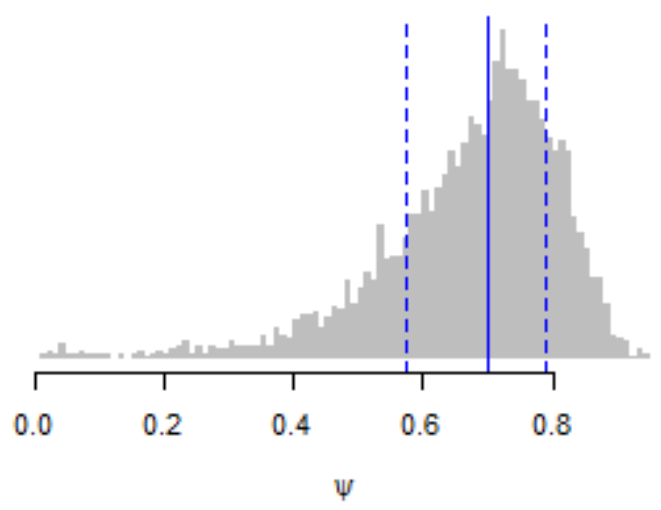

Figure 5. Posteriors on model estimates (a) abundance $N_{0}(b)$ The litter effect $v(c)$ The sex ratio $\zeta$ (d) $\theta$ multiple paternity (e) female partners per female estimate $\gamma(f)$ proportion of females skip spawning $\psi$. Vertical bars indicate median (solid line) and $80 \%$ credible intervals (for 95\% CI summaries, see table 2). 


\section{Supplementary Material}

\section{Appendix A - CKMR likelihood calculations}

To define the various combinations of HSP probabilities we first consider the within-cohort $\left(c_{i}=c_{j}\right)$ and then consider cross cohort situation. Throughout we define where the set of kintypes as $\mathcal{K}=\{F S P, M H S P, P H S P\}$. The following terms are used in the likelihood.

- The $v$ term is the litter effect. This describes the potential for over-representation of withincohort maternal kin (FSPs and MHSPs) given high heterogeneity in very early-life survival. For example: some litters are by chance missed by all predators such as crocodiles, whereas another may be subject to $100 \%$ predation.

- The $\theta$ term is the probability that a mother will mate with more than one male in a given year i.e. multiple paternity litters.

- $\quad$ The $\gamma$ term is present to permit the possibility of individual fathers mating with multiple females in a given year

- The HSP false-neg probability $\pi_{\eta}^{h s p}$ is included to take care of the fact that we know we removed a certain fraction of true HSPs away to ensure we avoid false positives in the final sample.

- The critical HSP PLOD $\eta$ is the threshold such that we expect less than 1 non-HSP appearing above it; for this example $\pi_{\eta}^{h s p}=0.92$ (with HTPs being the critical kin for defining where $\eta$ was). For FSPs there it was clear from their PLODs scores relative to other kintypes so we assumed that $\pi^{f s p}=1$.

We now consider the cases of within and cross-cohort comparisons and their associated kin-pair probabilities.

\section{Within-cohort comparisons}

For the Full-Sibling Pair (FSP) case:

$$
\mathbb{P}\left(k_{i j}=F S P \mid \mathbf{z}, \eta\right)=\frac{v(1-\theta)}{N_{f, c_{i}}}
$$

and for Maternal HSPs (MHSPs):

$$
\mathbb{P}\left(k_{i j}=\operatorname{MHSP} \mid \mathbf{z}, \eta\right)=\frac{\pi_{\eta}^{h s p} v \theta}{N_{f, c_{i}}}
$$

Now consider Paternal HSPs (PHSPs): 


$$
\mathbb{P}\left(k_{i j}=\operatorname{PHSP} \mid \mathbf{z}, \eta\right)=\frac{\pi_{\eta}^{h s p} \gamma}{N_{m, c_{i}}}
$$

\section{Cross-cohort comparisons}

Dealing with the cross-cohort case now $\left(c_{i} \neq c_{j}\right)$ then for MHSPs (assuming cross-cohort FSPs to be basically zero probability):

$$
\mathbb{P}\left(k_{i j}=\operatorname{MHSP} \mid \mathbf{z}, \eta\right)=\frac{\phi^{\delta}}{N_{f}}
$$

where $\delta=c_{i}-c_{j}$. The same general expression applies to cross-cohort PHSPs (just swap $f$ for $m)$. The overall negative log likelihood is therefore given by

$$
\mathcal{L}\left(N_{0}, \lambda, \phi, \mid \mathbf{Z}\right)=\sum_{i} \sum_{j} \log \left(p_{i j}^{k i n}\right)
$$

where

$p_{i j}^{k i n}=\left\{\begin{array}{l}\mathbb{P}\left(k_{i j}=M H S P \mid \mathbf{z}, \eta\right)+\mathbb{P}\left(k_{i j}=P H S P \mid \mathbf{z}, \eta\right)+\mathbb{P}\left(k_{i j}=F S P \mid \mathbf{z}, \eta\right) \quad \text { if } \quad \kappa \in \mathcal{K} \\ 1-\left[\mathbb{P}\left(k_{i j}=M H S P \mid \mathbf{z}, \eta\right)+\mathbb{P}\left(k_{i j}=P H S P \mid \mathbf{z}, \eta\right)+\mathbb{P}\left(k_{i j}=F S P \mid \mathbf{z}, \eta\right)\right] \quad \text { if } \quad \kappa \notin \mathcal{K}\end{array}\right.$

\section{Inclusion of mitochondrial DNA}

Mitochondrial DNA provides information on the following question: given the covariates, $\mathbf{z}$, and the critical PLOD, $\eta$, do the compared individuals have the same haplotype or not?

The approach we take is to split the cases into three groups:

- $\quad$ Case 1: Probability that you are above some PLOD value $\eta^{\prime}$, where $\eta^{\prime}>\eta$, and are a FSP only (and therefore both must have the same haplotype, i.e. $h_{2}=h_{1}$ )

- $\quad$ Case 2: Probability that the PLOD is between $\eta$ and $\eta^{\prime}$ (i.e. and are HSP) and $h_{2}=h_{1}$

- $\quad$ Case 3: Probability that your PLOD is between $\eta$ and $\eta^{\prime}$ (i.e. and are HSP) and the haplotypes differ $\left(h_{2} \neq h_{1}\right)$

The are two steps to populating the probabilities that go along with these three cases: (i) calculate them as 'raw' probabilities given the PLOD and covariates for each comparison above the critical PLOD, $\eta$; and (ii) normalise them to form a categorical distribution with the three cases as outlined above. For case 1 (PLOD $\left.>\eta^{\prime}\right)$ the raw probability is just $p_{1}=\mathbb{P}(k=F S P \mid \mathbf{z}, \eta)$. For case $2\left(\operatorname{PLOD} \in\left(\eta, \eta^{\prime}\right)\right.$ and $\left.h_{2}=h_{1}\right)$ is is defined as follows:

$$
\begin{gathered}
p_{2}=\mathbb{P}(k=M H S P \mid \mathbf{z}, \eta) \times \pi\left(h_{2}=h_{1} \mid h_{1}, k=M H S P\right)+ \\
\mathbb{P}(k=P H S P \mid \mathbf{z}, \eta) \pi\left(h_{2}=h_{1} \mid h_{1}, k=P H S P\right),
\end{gathered}
$$

and for case 3 we have that 


$$
\begin{gathered}
p_{3}=\quad \mathbb{P}(k=M H S P \mid \mathbf{z}, \eta) \times \pi\left(h_{2} \neq h_{1} \mid h_{1}, k=M H S P\right)+ \\
\mathbb{P}(k=P H S P \mid \mathbf{z}, \eta) \pi\left(h_{2} \neq h_{1} \mid h_{1}, k=P H S P\right)
\end{gathered}
$$

For MHSPs $\pi\left(h_{2}=h_{1} \mid h_{1}, k\right)=1$ and $\pi\left(h_{2} \neq h_{1} \mid h_{1}, k\right)=0$; for PHSPs $\pi\left(h_{2}=h_{1} \mid h_{1}, k\right)=$ $\mathbb{P}\left(h_{2}\right)$ and $\pi\left(h_{2} \neq h_{1} \mid h_{1}, k\right)=1-\mathbb{P}\left(h_{2}\right)$. These three probabilities are then normalised to sum to 1

$$
p_{m}^{m t}=\frac{p_{m}}{\sum_{n=1}^{3} p_{n}}
$$

So for every case, $m$, where we have an identified kin-pair above the critical PLOD $\eta$ we add $\log \left(p_{m}^{m t}\right)$ to the $\log$-likelihood, depending on which of three cases happens to cover that particular comparison that found the kin-pair. The last bit of the likelihood (which is Bernoulli) will then be the nuclear DNA component describing the probability of being "above the $\eta$ line":

$$
\mathbb{P}\left(P L O D_{i j}>\eta \mid \mathbf{z}\right)=\sum_{k \in \mathcal{K}} \mathbb{P}(k \mid \mathbf{z}, \eta),
$$

computed over all possible $\{i, j\}$ comparisons. 


\section{Appendix B. Simple estimator of abundance from CKMR accounting for sex ratio}

First, note that we must use only across-cohort comparisons $\widetilde{N}_{c}$ and HSPs $\widetilde{N}_{k}$ to avoid biasing abundance calculations. However in the present case we need to account for the sex ratio $\zeta$ given we have indications of a significant skew. Following Hillary et al (2018), the further components we need (and the values from our study) are: 1. Mean difference in birth years of across-cohort comps $\delta$ (2) 2. Adult survival rate (assumed same across sexes), $\phi(0.8807971) 3$. False negative retention probability, $\pi_{\eta}(0.92)$ We also set $\zeta=0.11$ and note that we have $N_{c}=4094$ and $N_{k}=35$. From these quantitites, the approximate probability of getting the total number of HSPs is as follows:

$$
\begin{aligned}
p_{h s p} & =\pi_{\eta} \phi^{\delta}\left(\frac{1}{\zeta N_{A}}+\frac{1}{(1-\zeta) N_{A}}\right) \\
& =\pi_{\eta} \phi^{\delta}\left(\frac{1}{\zeta(1-\zeta) N_{A}}\right)
\end{aligned}
$$

Recall that there is a simple relationship between the number of HSP and the number of comparisons:

$$
\widetilde{N}_{k}=p_{h s p} \widetilde{N}_{c}
$$

Now we use this to get an estimate of $N_{A}$ :

$$
\widehat{N}_{A}=\frac{\widetilde{N}_{c} \pi_{\eta} \phi^{\delta}}{\zeta(1-\zeta) \widetilde{N}_{k}}
$$

So in the Fisherian case, $\zeta=0.5$ and the equation contains the standard factor of 4 ;

$$
\widehat{N}_{A}=\frac{1}{4} \frac{\widetilde{N}_{c}}{\widetilde{N}_{k}} \pi_{\eta} \phi^{\delta}
$$

as per Hillary et al (2018). These calculations give an estimate of abundance as $\widehat{N}=852.7793196$, which is close to our estimate from the full model (see table 2 and figure 4 in the main text). Note also that as the sex ratio becomes skewed toward dominance by either sex, the population size goes up and that the lowest population size estimate is at a 1:1 sex ratio. 


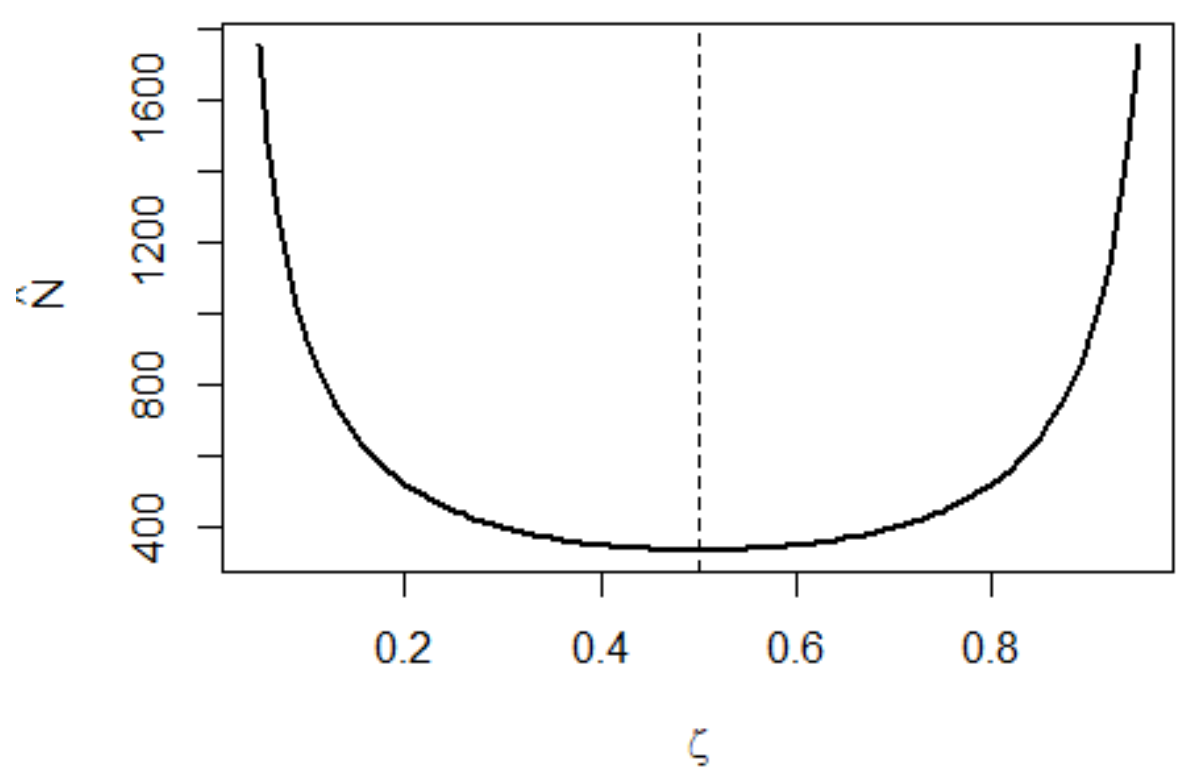

Figure S3. The relationship between sex ratio $\zeta$ and the estimated population size $\widehat{N}$ from the simple estimator and with values derived from our data. This shows that the lowest population size would be expected at 50:50 sex ratio. 